\title{
THE APPLICATION OF UML IN THE PROTOTYPE OF DESIGN EXPERT SYSTEM FOR THE DIAGNOSIS OF CHILI DISEASES AND PESTS
}

\author{
Muliadi', Irwan Budiman² , Antar Sofyan ${ }^{3}$ \\ 1,2,Prodi Ilmu Komputer FMIPA ULM \\ 3Prodi Ilmu Pertanian FAPERTA ULM \\ Jl. A. Yani Km 36 Banjarbaru, Kalimantan selatan \\ 1Email : Muliadi@unlam.ac.id
}

\begin{abstract}
Prototype or archetype is the initial form or standard size of an entity. In the design field, a prototype is made before it is developed or precisely made specifically for development before it is made on an actual scale or before mass produced, it will feel very difficult if you do not have a compounding model to design a system. Therefore, to design a prototype expert system for diagnosing diseases and pests of chilli plants using the Unified Modeling Language (UML) method. The purpose of the implementation of this model is to meet all user needs for the software to be built. Manfaat dari model ini dapat membantu perancang perangkat lunak dalam membangun sistem pakar untuk mendiagnosis penyakit dan hama tanaman cabai. The result of this UML implementation is to obtain use case of system processing, diagram activity, entity relationship diagram, and form input output design.
\end{abstract}

Keywords: Unified Modeling Language (UML), Design, prototype, Expert System Prototype, Chili Plant.

\section{PENERAPAN UML PADA PERANCANGAN PURWARUPA SISTEM PAKAR DIAGNOSA PENYAKIT DAN HAMA TANAMAN CABAI}

\begin{abstract}
Abstrak
Purwarupa atau arketipe atau prototype merupakan bentuk awal atau standar ukuran dari sebuah entitas. Pada bidang desain, sebuah prototipe dibuat sebelum dikembangkan atau justru dibuat khusus untuk pengembangan sebelum dibuat dalam skala sebenarnya atau sebelum diproduksi secara massal, akan terasa sangat kesulitan jika tidak memilik model peracangan untuk merancang sebuat system. Oleh sebab untuk merancang purwarupa system pakar diagnosa penyakit dan hama tanaman cabai menggunakan metode Unified Modelling Language (UML). Tujuan dari penerapan model ini adalah untuk memenuhi semua kebutuhan pengguna terhadap perangkat lunak yang akan dibangun. Manfaat dari model ini dapat membantu desainer perangkat lunak dalam membangun system pakar diagnosa penyakit dan hama tanaman cabai. Hasil dari penerapan UML ini adalah memperoleh use case proses sistem, activity digram sistem, entity relationship diagram, dan rancangan form input output.
\end{abstract}

Kata kunci : Unified Modelling Language (UML), Perancangan, Purwarupa, Prototype Sistem Pakar, Tanaman Cabai. 


\section{PENDAHULUAN}

Purwarupa atau arketipe atau prototype merupakan bentuk awal atau standar ukuran dari sebuah entitas. Pada bidang desain, sebuah prototipe dibuat sebelum dikembangkan atau justru dibuat khusus untuk pengembangan sebelum dibuat dalam skala sebenarnya atau sebelum diproduksi secara massal

Sistem Pakar (expert system) adalah sistem yang berusaha mengadopsi pengetahuan manusia ke komputer agar komputer dapat menyelesaikan masalah seperti yang biasa dilakukan oleh para ahli. Sistem pakar yang baik dirancang agar dapat menyelesaikan suatu permasalahan tertentu dengan meniru kerja dari para ahli. Dengan sistem pakar ini, orang awam dapat menyelesaikan masalah yang cukup rumit yang sebenarnya hanya dapat diselesaikan dengan bantuan para ahli. Dalam merancang perangkat lunak sistem pakar di perlukan suatu model. Untuk dapat membantu proses perancangan dan pengembangan proses aktifitas pada rekayasa perangkat lunak sistem pakar tersebut., maka dipilihlah Unified Modeling Language (UML) sebagai alat bantu untuk merancang perangkat lunak system pakar diagnose penyakit dan hama tanaman cabai.

Unified Modelling Language (UML) adalah sebuah "bahasa" yang telah menjadi standar dalam industri untuk visualisasi, merancang dan mendokumentasikan sistem piranti lunak. UML menawarkan sebuah standar untuk merancang model sebuah system[1]. akan terasa sangat kesulitan jika tidak memilik model peracangan untuk merancang sebuat system. Oleh sebab untuk merancang purwarupa system pakar diagnosa penyakit dan hama tanaman cabai menggunakan metode Unified Modelling Language (UML).

\section{METODE PENELITIAN}

Metede penelitian untuk perancangan purwarupa diagnosa penyakit tanaman cabai ini menggunakan Unified Modelling Language (UML). Pemodelan (modeling) adalah proses merancang piranti lunak sebelum melakukan pengkodean (coding). Model piranti lunak dapat dianalogikan seperti blueprint pada pembangunan gedung.

Membuat model dari sebuah sistem yang kompleks sangatlah penting karena untuk dapat memahami sistem secara menyeluruh tidak mudah, UML merupakan teknik pemodelan yang tepat digunakan untuk pengembangan perangkat lunak sehingga perencanaan pembangunanan sistem akan tertata rapi kususnya untuk aplikasi berorientasi object[1][2][3].

Dengan menggunakan UML, diharapkan pengembangan piranti lunak dapat memenuhi semua kebutuhan pengguna dengan lengkap dan tepat, termasuk faktorfaktor seperti scalability, robustness, security, dan sebagainya[3].

Dalam perancangan purwarupa diagonosa hama dan penyakit tanaman cabai ini melakukan beberapa rancangan diataranya:

a. Use Case Proses Sistem

Use case merupakan bagian dari UML yang digunakan untuk merancang proses yang terjadi pada system. Use Case menjelaskan interaksi yang terjadi antara actor dan inisiator yang saling berinteraksi. 
b. Activity Digram Sistem

Activity Diagram merupakan alur kerja (workflow) atau kegiatan (activity) dari sebuah sistem. Activity Diagram juga digunakan untuk mendefinisikan urutan atau pengelompokan tampilan dari sistem (user interface).

c. Entity Relationship Diagram (ERD)

Entity Relationship Diagram adalah suatu model untuk menjelaskan hubungan antar data dalam basis data berdasarkan objek-objek dasar data yang mempunyai hubungan antar relasi yang biasa disebut dengan Relasi antar Entitas.

\section{HASIL DAN PEMBAHASAN}

Use case mendeskripsikan sistem, lingkungan, serta hubungan antara sistem dengan lingkungannya. Berikut perancangan use case purwarupa sistem diagnosa penyakit tanaman cabai:

a. Use Case Proses Diagnosa

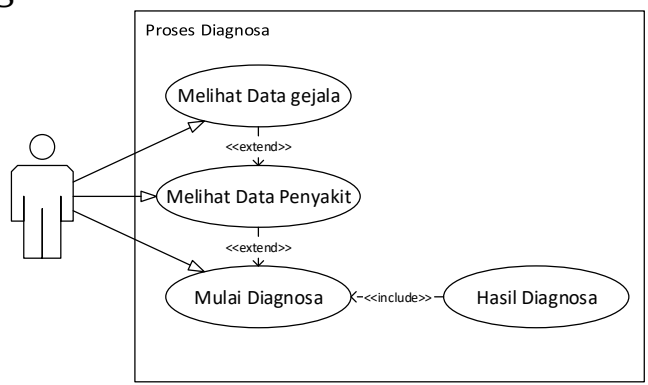

Gambar 1. Use Case Proses Diagnosa

Pada gambar1 terdapat 4 proses yang dapat dideskripsikan diantarnya adalah:

1) Mulai Diagnosa

Tabel 1. UCD Mulai Diagnosa

\begin{tabular}{ll}
\hline Atribut & Keterangan \\
\hline $\begin{array}{l}\text { Short } \\
\text { Description }\end{array}$ & $\begin{array}{l}\text { Use case ini untuk } \\
\text { melakukan proses } \\
\text { diagnosa }\end{array}$ \\
\hline Actor & User \\
\hline Pre Condition & Form Konsultasi \\
\hline $\begin{array}{l}\text { Post } \\
\text { Condition }\end{array}$ & Form Konsultasi \\
\hline Normal Flow & $\begin{array}{l}\text { User memilih gejala- } \\
\text { gejala } \\
\text { Menekan tombol }\end{array}$ \\
\hline Alternative & $\begin{array}{l}\text { User membatalkan } \\
\text { proses memilih } \\
\text { gejala }\end{array}$ \\
\hline
\end{tabular}

Exception

Flow

2) Data gejala

Tabel 2. UCD Data Gejala

\begin{tabular}{ll}
\hline Atribut & Keterangan \\
\hline $\begin{array}{l}\text { Short } \\
\text { Description }\end{array}$ & $\begin{array}{l}\text { Use case ini untuk } \\
\text { melihat data gejala }\end{array}$ \\
\hline Actor & User \\
\hline Pre Condition & Form Beranda \\
\hline $\begin{array}{l}\text { Post } \\
\text { Condition }\end{array}$ & Form Beranda \\
\hline Normal Flow & $\begin{array}{l}\text { User melihat data } \\
\text { gejala }\end{array}$ \\
\hline $\begin{array}{l}\text { Alternative } \\
\text { Flow }\end{array}$ & - \\
\hline $\begin{array}{l}\text { Exception } \\
\text { Flow }\end{array}$ & - \\
\hline
\end{tabular}


3) Data Peyakit

Tabel 3. UCD Data Penyakit

\begin{tabular}{ll}
\hline Atribut & Keterangan \\
\hline $\begin{array}{l}\text { Short } \\
\text { Description }\end{array}$ & $\begin{array}{l}\text { Use case ini untuk } \\
\text { melihat data } \\
\text { penyakit }\end{array}$ \\
\hline Actor & User \\
\hline Pre Condition & Form Beranda \\
\hline $\begin{array}{l}\text { Post } \\
\text { Condition }\end{array}$ & Form Beranda \\
\hline Normal Flow & $\begin{array}{l}\text { User melihat data } \\
\text { penyakit }\end{array}$ \\
\hline $\begin{array}{l}\text { Alternative } \\
\text { Flow }\end{array}$ & - \\
\hline Exception & - \\
Flow & \\
\hline
\end{tabular}

4) Hasil Diagnosa

Tabel 4. UCD Hasil Diagnosa

\begin{tabular}{|c|c|}
\hline Atribut & Keterangan \\
\hline $\begin{array}{l}\text { Short } \\
\text { Description }\end{array}$ & $\begin{array}{l}\text { Use case ini untuk } \\
\text { melihat hasil diagnosa }\end{array}$ \\
\hline Actor & User \\
\hline Pre Condition & Form Konsultasi \\
\hline $\begin{array}{l}\text { Post } \\
\text { Condition }\end{array}$ & Form Hasil \\
\hline Normal Flow & $\begin{array}{l}\text { Sistem Memproses Gejala } \\
\text { yang dipilih } \\
\text { Sistem Menampilkan } \\
\text { Hasil }\end{array}$ \\
\hline $\begin{array}{l}\text { Alternative } \\
\text { Flow }\end{array}$ & 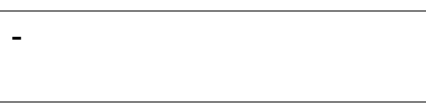 \\
\hline $\begin{array}{l}\text { Exception } \\
\text { Flow }\end{array}$ & - \\
\hline
\end{tabular}


b. Use Case Pengelolaan Data Gejala

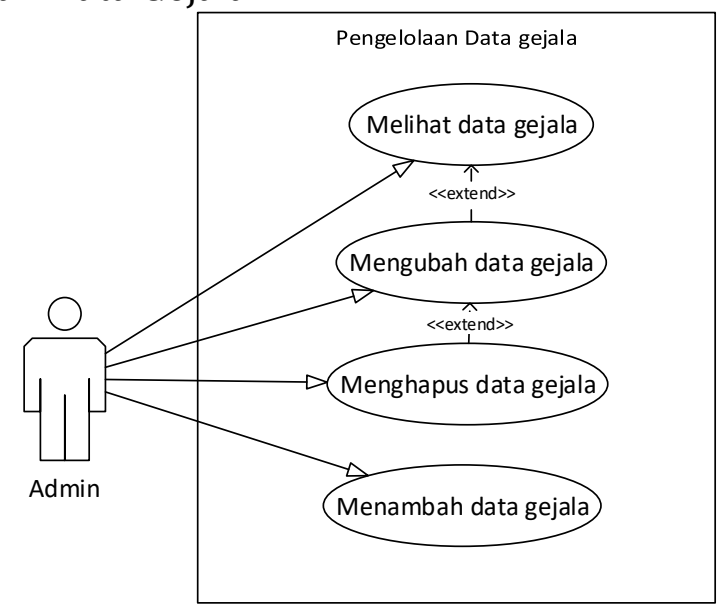

Gambar 2. Use Case Proses Diagnosa

Pada gambar2 terdapat 4 proses yang dapat dideskripsikan diantarnya adalah:

1) Tambah Data Gejala

Tabel 5. UCD Tambah Data Gejala

\begin{tabular}{ll}
\hline Atribut & Keterangan \\
\hline $\begin{array}{l}\text { Short } \\
\text { Description }\end{array}$ & $\begin{array}{l}\text { Use case ini untuk } \\
\text { menambah data gejala }\end{array}$ \\
\hline Actor & Admin \\
\hline Pre Condition & Form Data Gejala \\
\hline Post Condition & $\begin{array}{l}\text { Sistem menyimpan data } \\
\text { gejala }\end{array}$ \\
\hline Normal Flow & $\begin{array}{l}\text { - Menginput data gejala } \\
\text { - Memilih tombol }\end{array}$ \\
\hline Alternative & - \\
Flow & \\
\hline Exception Flow & - \\
\hline
\end{tabular}

2) Ubah Data Gejala

Tabel 6. UCD Edit Data Gejala

\begin{tabular}{ll}
\hline Atribut & Keterangan \\
\hline Short & Use case ini untuk \\
Description & mengubah data gejala \\
\hline Actor & Admin \\
\hline Pre Condition & Form data gejala \\
\hline Post & Sistem mengedit data \\
Condition & gejala \\
\hline Normal Flow & User memilih gejala \\
& $\begin{array}{l}\text { yang mau diedit } \\
\text { User mengedit data }\end{array}$ \\
& $\begin{array}{l}\text { Usere menekan tombol } \\
\text { simpan data }\end{array}$ \\
\hline Alternative & - \\
Flow & \\
\hline Exception & - \\
Flow & \\
\hline
\end{tabular}

3) Hapus Data Gejala

Tabel 7. UCD Hapus Data Gejala

\begin{tabular}{ll}
\hline Atribut & Keterangan \\
\hline Short & Use case ini untuk \\
Description & menghapus data gejala \\
\hline Actor & Admin \\
\hline
\end{tabular}




\begin{tabular}{ll}
\hline Pre Condition & Form data gejala \\
\hline $\begin{array}{l}\text { Post } \\
\text { Condition }\end{array}$ & $\begin{array}{l}\text { Sistem menghapus data } \\
\text { gejala }\end{array}$ \\
\hline Normal Flow & $\begin{array}{l}\text { User memilih gejala yang } \\
\text { mau dihapus }\end{array}$ \\
\hline $\begin{array}{l}\text { Alternative } \\
\text { Flow }\end{array}$ & - \\
\hline Exception & - \\
Flow & \\
\hline
\end{tabular}

4) Melihat Data Gejala

Tabel 8. UCD Melihat Data Gejala

\begin{tabular}{ll}
\hline Atribut & Keterangan \\
\hline Short Description & Use case ini untuk melihat data gejala \\
\hline Actor & Admin \\
\hline Pre Condition & Form data gejala \\
\hline Post Condition & Sistem menampilkan data gejala \\
\hline Normal Flow & - Memilih form data gejala \\
& - Melihat data gejala \\
\hline Alternative Flow & - \\
\hline Exception Flow & - \\
\hline
\end{tabular}

c. Use Case Pengelolaan Data Penyakit

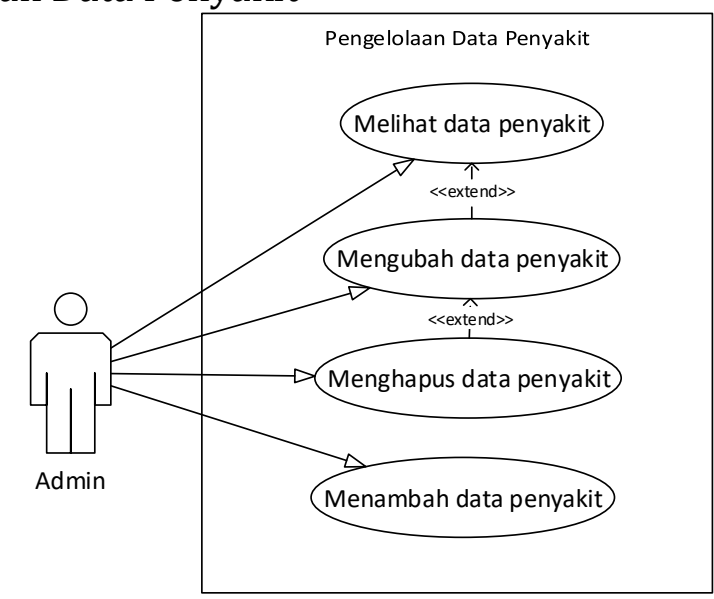

Gambar 3. UC Pengelolaan Data Penyakit

Pada gambar3 terdapat 4 proses yang dapat dideskripsikan diantarnya adalah:

1) Melihat Data Penyakit

Tabel 9. UCD Melihat Data Penyakit

\begin{tabular}{ll}
\hline Atribut & Keterangan \\
\hline Short & Use case ini untuk \\
Description & meilhat data penyakit
\end{tabular}

\begin{tabular}{|c|c|}
\hline Actor & Admin \\
\hline $\begin{array}{l}\text { Pre } \\
\text { Condition }\end{array}$ & Form data penyakit \\
\hline $\begin{array}{l}\text { Post } \\
\text { Condition }\end{array}$ & $\begin{array}{l}\text { Sistem menampilkan } \\
\text { data penyakut }\end{array}$ \\
\hline Normal Flow & $\begin{array}{l}\text { Memilih form data } \\
\text { penyakit }\end{array}$ \\
\hline
\end{tabular}




\begin{tabular}{ll}
\hline & Melihat data penyakit \\
\hline Alternative & - \\
Flow & \\
\hline Exception & - \\
Flow & \\
\hline
\end{tabular}

2) Mengubah Data Penyakit

Tabel 10. UCD Edit Data Penyakit

\begin{tabular}{ll}
\hline Atribut & Keterangan \\
\hline Short & Use case ini untuk \\
Description & mengubah data penyakit \\
\hline 3) Menghapus & Data Penyakit
\end{tabular}

Tabel 11. UCD Hapus Data Penyakit

3) Menghapus Data Penyakit

4) Menambah Data Penyakit

\begin{tabular}{ll}
\hline Actor & Admin \\
\hline Pre Condition & Form data penyakit \\
\hline Post & $\begin{array}{l}\text { Sistem mengedit data } \\
\text { penyakit }\end{array}$ \\
\hline Normal Flow & $\begin{array}{l}\text { User memilih penyakit } \\
\text { yang akan diedit } \\
\text { User mengedit data } \\
\text { User menekan tombol } \\
\text { simpan data }\end{array}$ \\
& - \\
Alternative & \\
Flow & Exception \\
Flow & \\
\hline
\end{tabular}

\begin{tabular}{|c|c|}
\hline Atribut & Keterangan \\
\hline Short Description & Use case ini untuk menghapus data penyakit \\
\hline Actor & Admin \\
\hline Pre Condition & Form data solusi penyakit \\
\hline Post Condition & Sistem menghapus data penyakit \\
\hline Normal Flow & $\begin{array}{l}\text { User memilih data penyakit yang akan dihapus } \\
\text { User memilih tombol hapus data }\end{array}$ \\
\hline Alternative Flow & - \\
\hline Exception Flow & - \\
\hline
\end{tabular}

Tabel 12. UCD Tambah Data Penyakit

\begin{tabular}{ll}
\hline Atribut & Keterangan \\
\hline Short Description & Use case ini untuk menambah data penyakit \\
\hline Actor & Admin \\
\hline Pre Condition & Form data penyakit \\
\hline Post Condition & Sistem menyimpan data penyakit \\
\hline Normal Flow & $\begin{array}{l}\text { User menekan tombol tambah penyakit } \\
\text { User menginput data penyakit }\end{array}$ \\
& User memilih tombol simpan \\
\hline Alternative Flow & - \\
\hline Exception Flow & - \\
\hline
\end{tabular}

Maka dilakukan begitu seterusnya sehinga pada proses perancangan use case diperoleh beberapa diataranya:
a. Use Case Proses Diagnosa
b. Use Case Pengelolaan Data Gejala
c. Use Case Pengelolaan Data Penyakit
d. Use Case Pengelolaan Basis Aturan
e. Use Case Pengelolaan Data Kategori 
f. Use Case Mulai Aplikasi

Selanjutnya perancangan aktivitas system. Terdapat beberapa activity diagram pada saat perancangan proses Activity Diagram Sistem Diagnosa Penyakit Tanaman Cabai diantaranya:
a. AD Memulai Diagnosa
b. AD Menampilkan Data Gejala
c. AD Menambah Data Gejala
d. AD Mengubah Data Gejala
e. AD Menghapus Data Gejala
f. AD Menampilkan Data Penyakit
g. AD Mengedit Data Penyakit
h. AD Menghapus Data Penyakit
i. AD Menambah Data Penyakit

j. AD Menampilkan Data Basis Aturan

k. AD Mengubah Data Basis Aturan

l. AD Menghapus Data Basis Aturan

m. AD Menambah Data Basis Aturan

n. AD Menampilkan Data Kategori

o. AD Mengubah Data Kategori

p. AD Menghapus Data Kategori

q. AD Menambah Data Kategori

r. AD Login Admin

Berikut ini contoh perancangann Activity Diagram memulai diagnosa yang ditunjukkan pada gambar 4. Activity diagram memulai diagnosa

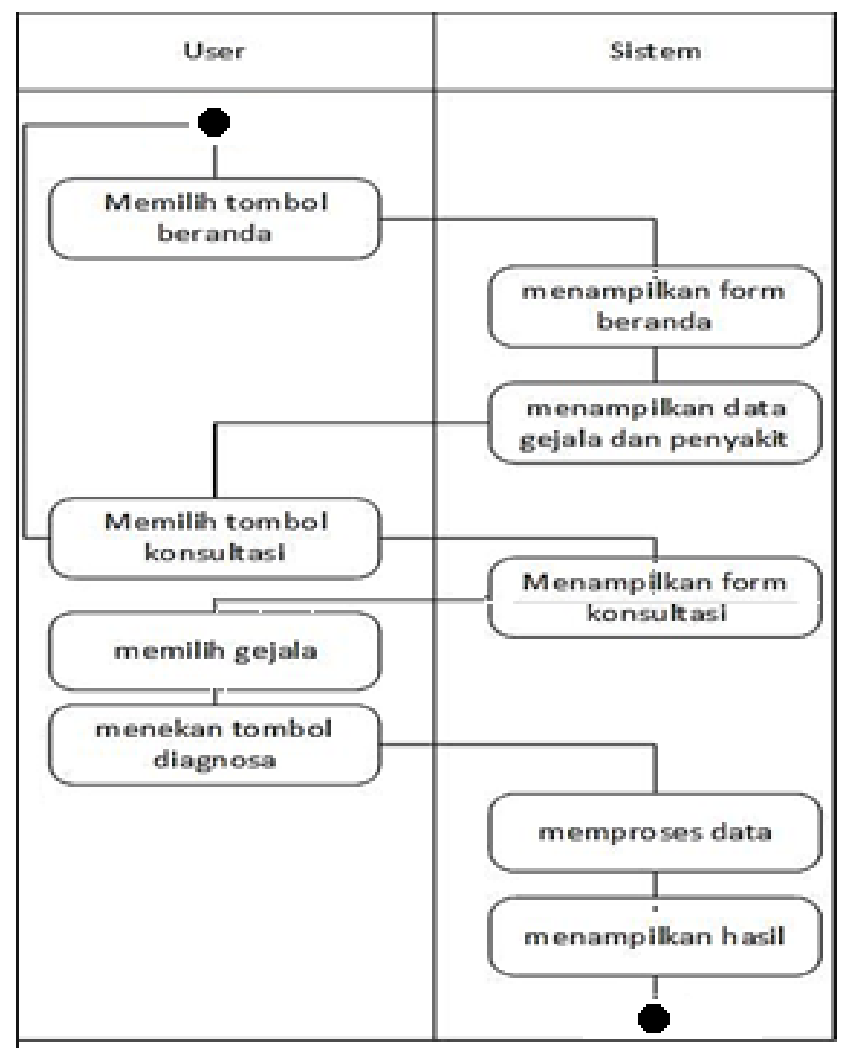

Gambar 4. AD Memulai Diagnosa

Proses perancangan Actitvity diagram dilakukan terus menerus sampai kepada activity diagram login admin.

Setelah dilakukan proses analisa sistem, maka tahap selanjutnya adalah melakukan perancangan database atau basis data. Perancangan basis data bertujuan untuk menggambarkan hubungan antar entitas yang ditunjukkan pada gambar 5 . 


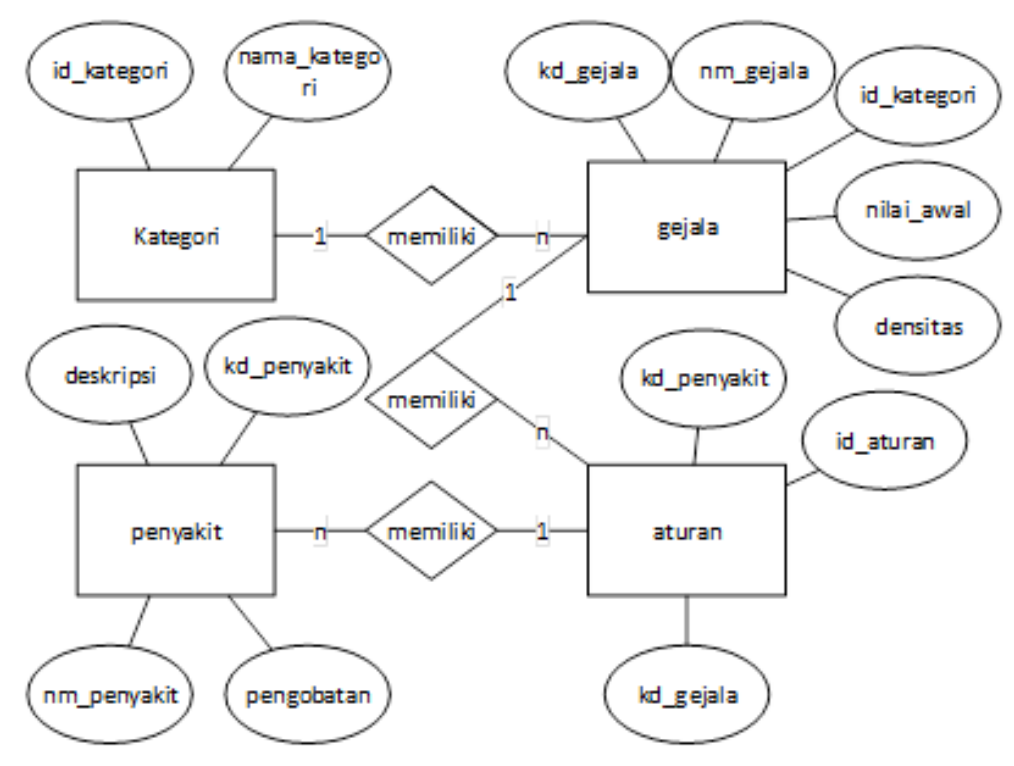

Gambar 5 Entity Relationship Diagram

Untuk selanjutnya melakukan perancangan user interface, terdapat beberapa rancangan form pada rancangan user interface Purwarupa Sistem Diagnosa Penyakit Tanaman Cabai ini diantaranya adalah:
a. Form Login
e. Form Data Kategori
b. Form Beranda
f. Form Data Penyakit
c. Form Konsultasi
g. Form Data Gejala
d. Form Hasil Diagnosa
h. Form Basis Aturan

Perancangan user interface ini dilakukan bertujuan untuk menggambarkan input data pada form yang akan disimpan pada basis data yang ditunjukkan pada gambar 6 .

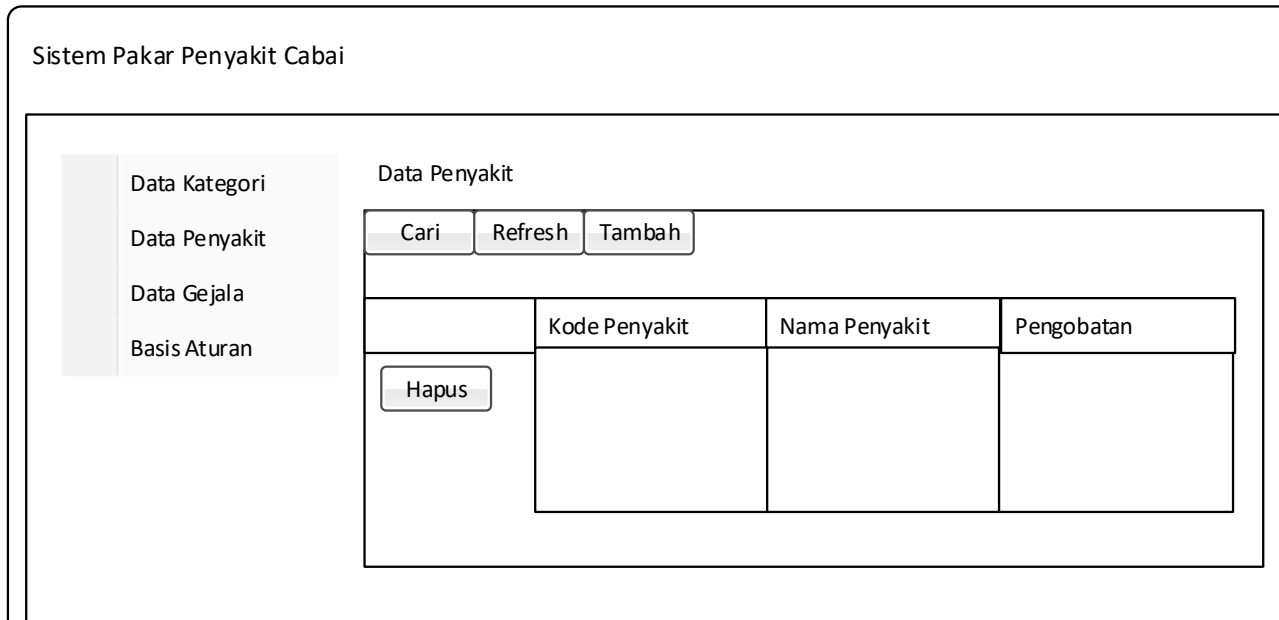

\section{Gambar 6. Contoh form input data penyakit}

Perancangan form ini dilakukan terus menerus mulai perancangan form login sampai dengan perancangan form basis aturan. Untuk selanjutnya melakukan implementasi 
rancangan pada pembangunan Sistem Diagnosa Penyakit Tanaman Cabai, berikut ini salah satu contoh hasil purwarupa form konsultasi diagonasa penyakit cabai yang telah didesain yang ditunjukan pada gambar 7 .

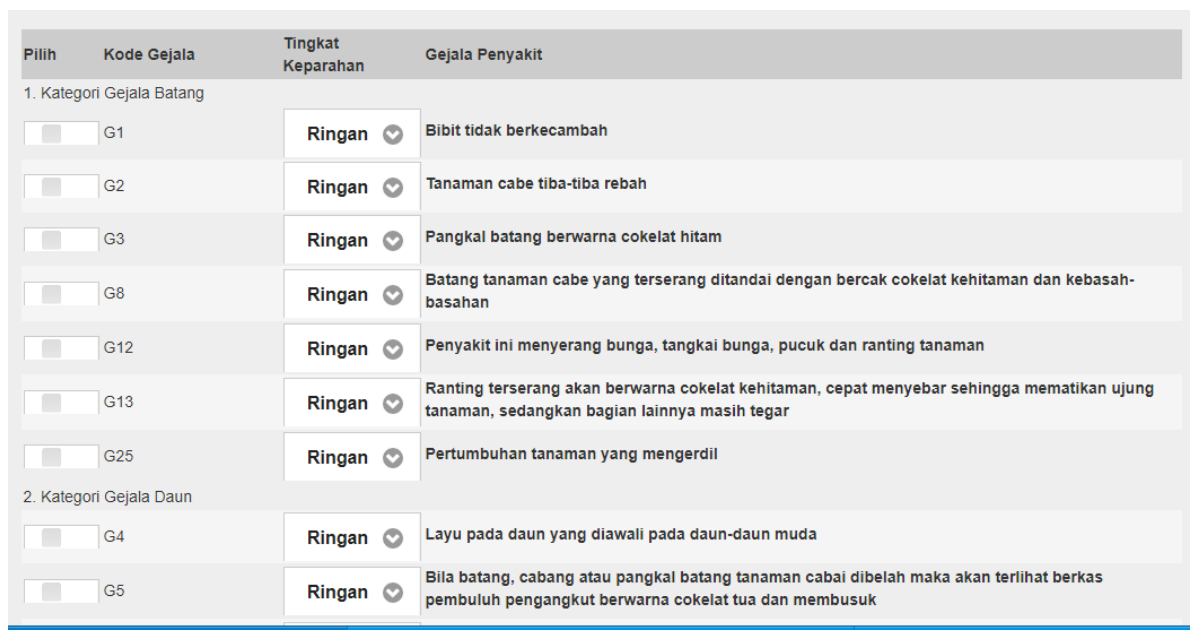

Gambar 7. Implementasi form konseltasi diagnosa penyakit tanaman cabai

\section{SIMPULAN}

Berdasarkan penarapan model Unified Modelling Language (UML) yang telah dilakukan maka diperoleh simpulan sebagai berikut:

a. Memperoleh diagram use case diataranya adalah use case proses diagnosa, use case pengelolaan data gejala, use case pengelolaan data penyakit, use case pengelolaan basis aturan, use case pengelolaan data kategori, use case mulai aplikasi.

b. Memperoleh diagram activity diantaranya adalah AD Memulai Diagnosa, AD Menampilkan Data Gejala, AD Menambah Data Gejala, AD Mengubah Data Gejala, AD Menghapus Data Gejala, AD Menampilkan Data Penyakit, AD Mengedit Data Penyakit, AD Menghapus Data Penyakit, AD Menambah Data Penyakit, AD Menampilkan Data Basis Aturan, AD Mengubah Data Basis Aturan, AD Menghapus Data Basis Aturan, AD Menambah Data Basis Aturan, AD Menampilkan Data Kategori, AD Mengubah Data Kategori, AD Menghapus Data Kategori, AD Menambah Data Kategori, AD Login admin.

c. Memperoleh diagram relasi antar entitias.

d. Memperoleh hasil rancagan form input ouput system.

\section{DAFTAR PUSTAKA}

[1] Grady Booch, James Rumbaugh, and Ivar Jacobson, "The Unified Modeling Language User Guide", Addison-Wesley, 1999.

[2] Ivar Jacobson, Grady Booch, and James Rumbaugh, "The Unified Software Development Process", Addison-Wesley, 1999.

[3] James Rumbaugh, Ivar Jacobson, and Grady Booch, "The Unified Modeling Language Reference Manual", Addison-Wesley, 1999.

[4] Muliadi, Irwan budiman, el. al, "FUZZY DAN DEMPSTER-SHAFER PADA SISTEM PAKAR DIAGNOSA PENYAKIT TANAMAN CABAI,” Vol.5 No.1, klik, 2017. 